\title{
Preferential Gq signaling in diabetes: an electrical switch in incretin action and in diabetes progression?
}

\author{
Colin G. Nichols, ${ }^{1,2}$ Nathaniel W. York, ${ }^{1,2}$ and Maria S. Remedi ${ }^{1,3}$ \\ 'Center for the Investigation of Membrane Excitability Diseases, ${ }^{2}$ Department of Cell Biology and Physiology, ${ }^{3}$ Division of Endocrinology, Department of Medicine, Washington University School of Medicine, \\ St. Louis, Missouri, USA.
}

\begin{abstract}
Patients with type 2 diabetes (T2D) fail to secrete insulin in response to increased glucose levels that occur with eating. Glucagon-like peptide-1 (CLP-1) and glucose-dependent insulinotropic polypeptide (CIP) are two incretins secreted from gastrointestinal cells that amplify insulin secretion when glucose is high. In this issue of the $J C l$, Oduori et al. explore the role of ATP-sensitive $\mathrm{K}^{+}\left(\mathrm{K}_{\mathrm{ATP}}\right)$ channels in maintaining glucose homeostasis. In persistently depolarized $\beta$ cells from $K_{A T P}$ channel knockout (KO) mice, the researchers revealed a shift in $G$ protein signaling from the Gs family to the Gq family. This shift explains why GLP-1, which signals via Gq, but not GIP, which signals preferentially via Gs, can effectively potentiate secretion in islets from the $\mathrm{K}_{\text {ATP }}$ channel-deficient mice and in other models of $\mathrm{K}_{\text {ATP }}$ deficiency, including diabetic KK-Ay mice. Their results provide one explanation for differential insulinotropic potential of incretins in human T2D and point to a potentially unifying model for T2D progression itself.
\end{abstract}

Switching G protein signaling in hyperexcited $\beta$ cells

The textbook progression of type 2 diabetes (T2D) involves development of insulin resistance that is frequently associated with obesity and that is initially compensated by increased insulin secretion from pancreatic $\beta$ cells. As insulin resistance increases, $\beta$ cells eventually fail to keep up and gradually cross over to an insulin undersecreting phenotype, at which point hyperglycemia develops, in turn worsening $\beta$ cell function (Figure 1A). While no panacea has yet arrived to stop the progression of T2D, agents that stimulate the so-called amplifying pathway of insulin secretion have proven effective at maintaining insulin secretion in diabetic individuals. Insulin secretion requires elevated intracellular calcium concentration ([Ca]), and is amplified by elevation of cAMP or diacylglycerol (DAG)/inositol 1, 4, 5 trisphosphate $\left(\mathrm{IP}_{3}\right)$ in response to activation of $\mathrm{G}$ proteins $\mathrm{Gs}$ and $\mathrm{Gq}$, respectively (1, 2). The incretins glucagon-like peptide-1 (GLP-1) and glucose-dependent insulinotropic polypeptide (GIP), released by enteroendocrine $\mathrm{L}$ cells and $\mathrm{K}$ cells following meal ingestion, bind to cognate receptors on the $\beta$ cell membrane, activating these pathways (3). Intriguingly, and thus far unexplained, GIP-induced insulin secretion (GIPIIS) is lost in T2D individuals, whereas GLP-1 action is preserved, accounting for the therapeutic efficacy of GLP-1 receptor agonists in T2D (4).

A metabolically generated rise in ATP concentration, and fall in ADP concentration, initiates $\beta$ cell ATP-sensitive $\mathrm{K}^{+}\left(\mathrm{K}_{\text {ATP }}\right)$ channel closure, which results in action potential firing and glucose-induced insulin secretion (GIIS). This electrical activity in turn elevates cytosolic [Ca], which triggers fusion of exocytotic vesicles (5). Accordingly, partial loss of function of $\mathrm{K}_{\mathrm{ATP}}$ channels increases electrical excitability
Related Article: p. 6639

Conflict of interest: The authors have declared that no conflict of interest exists.

Copyright: (c) 2020, American Society for Clinical Investigation.

Reference information: / Clin Invest. 2020;130(12):6235-6237. https://doi.org/10.1172/JCl143199. and insulin secretion, resulting in hyperinsulinemia in humans $(6,7)$ and in mice that have incomplete genetic knockout $(\mathrm{KO})$ or knockdown of $\mathrm{K}_{\text {ATP }}$ channels $(8,9)$. Complete loss of $\mathrm{K}_{\mathrm{ATP}}$ channels (in which either the pore-forming Kir6.2 or regulatory SUR1 subunits are genetically knocked out) causes permanent depolarization and hence chronically elevated [Ca] at all glucose levels (10-12). Paradoxically - as we will come back to below - these $\mathrm{K}_{\text {ATP }}$ channel-KO animals do not show hypersecretion. For unknown reasons, there is a downregulation of secretion itself, resulting in GIIS deficiency. These animals are actually glucose intolerant under normal conditions and, when fed a high-fat diet, prone to develop overt diabetes (13).

Oduori et al. (14) follow up on their earlier studies, which showed that GLP-1 induced insulin secretion (GLP-1IIS) from perfused pancreas was partially retained, while GIPIIS was severely diminished in these $\mathrm{K}_{\mathrm{ATP}}-\mathrm{KO}$ mice (15). They now show that $\beta$ cell-specific Kir6.2-KO mice $\left(\beta \mathrm{Kcnj11}^{-/-}\right.$mice) also exhibit severe glucose intolerance and impaired GIIS and that insulin secretion can be stimulated by GLP-1, but not by GIP, confirming that the $\mathrm{K}_{\mathrm{ATP}}-\mathrm{KO}$ phenotype reflects $\beta$ cell-specific phenomena. By careful and extensive biochemical and pharmacological studies, Oduori et al. (14) show that GLP-1 sensitivity (and GIP insensitivity) in these hyperexcited $\beta$ cells results from a relative shift from Gs to Gq signaling. Notably, membrane potential can modulate GPCRs, and sodium ions can allosterically affect class A GPCRs to modulate activation and signaling. Oduori et al. (14) suggest that persistent $\beta$ cell depolarization might induce a signaling bias, from Gs to Gq signaling, by chronically elevating internal sodium concentration. However, calcium control of $G$ protein function may offer an alternative explanation.

In and of themselves, the Oduori et al. experiments are constrained and clear, 
A

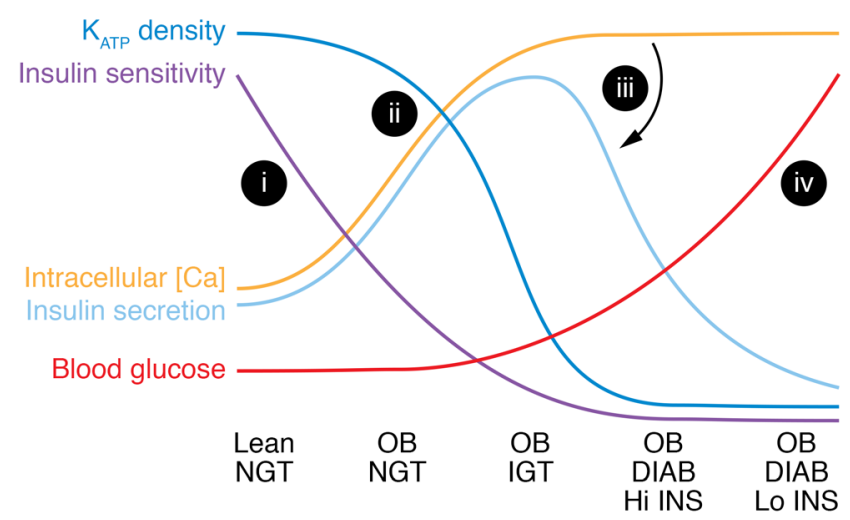

Figure 1. Model for T2D progression and treatment. (A) (i) Lean individuals with normal glucose tolerance (NGT) develop increasing obesity (OB), which reduces insulin sensitivity. (ii) Pancreatic $\beta$ cells respond by reducing $\mathrm{K}_{\text {ATP }}$ current density and increasing excitability/mean intracellular [Ca], which initially results in increased insulin secretion, maintaining normal blood glucose. However, above a certain level (iii), high excitability/intracellular [Ca] paradoxically inhibits insulin secretion itself (indicated by arrow). Impaired glucose tolerance (ICT) then progresses to overt diabetes (DIAB), coupled to an inexorable rise in blood glucose (iv), as the initially compensatory hyperinsulinemia (Hi INS) progresses to hypoinsulinemia (Lo INS). (B) As Oduori et al. (14) show, the same hyperexcitability that drives the switch to low insulin secretion also drives a shift of GPCR coupling from Gs to Gq. Consequently, GLP-1 treatment (acting via Gq) can maintain amplification of insulin secretion and, hence, slow the rise of blood glucose (indicated by arrows), whereas GIP (which does not couple to Gq) would have little to no effect.

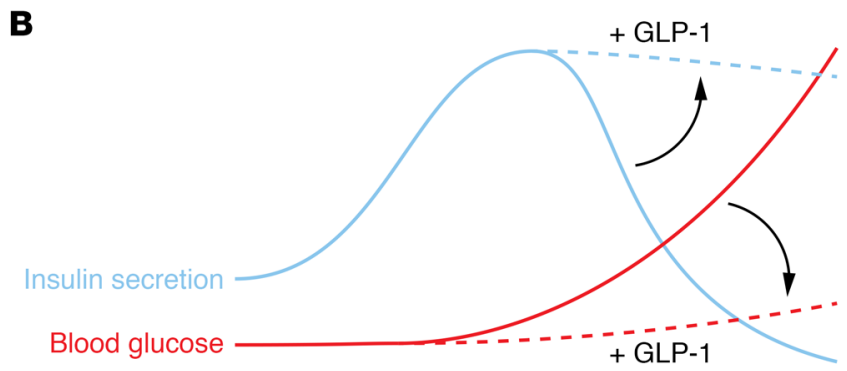

elegantly explaining the shift in incretin sensitivity in $\mathrm{K}_{\mathrm{ATP}}-\mathrm{KO} \beta$ cells. But the authors then draw on additional disparate animal and cellular models to weave a much broader tale that may have substantial importance for T2D - broader perhaps than even the authors are willing to imply. To examine the general hypothesis that persistent depolarization (of any cause) will result in enhanced Gq signaling, they carried out experiments on two models of chronic depolarization in isolated WT mouse islets cultured (a) in the sulfonylurea tolbutamide ( $500 \mu \mathrm{M}$ for 5 days) and (b) with high $(25 \mathrm{mM})$ glucose for 3 days as well as human islets cultured (c) in low (5.5 mM) or high $(16.7 \mathrm{mM})$ glucose for 3 days. All of these conditions likely caused chronic $\mathrm{K}_{\text {ATP }}$ channel closure during the treatment. However, as we have also shown (16), the authors report that even following such treatments, $\mathrm{K}_{\mathrm{ATP}}$ channels remained suppressed and $\beta$ cells were still depolarized and still fired action potentials when subsequently assessed in low $(1 \mathrm{mM})$ glucose. Moreover, $\beta$ cells failed to depolarize further when glucose was raised to $10 \mathrm{mM}$, implying that either $\mathrm{K}_{\text {ATP }}$ channels stayed closed or that they were no longer present. Surprisingly, the authors do not comment on why $\mathrm{K}_{\mathrm{ATP}}$ channel activity was gone, but they do show that in each model, the chronic depolarization in culture indeed led to maintenance of GLP-1IIS and loss of GIPIIS (14).

\section{G protein signaling switch as a fundamental T2D mechanism?}

Without explicitly stating the underlying hypothesis that $\mathrm{T} 2 \mathrm{D}$ progression should involve chronic loss of $\mathrm{K}_{\mathrm{ATP}}$ and depolarization, Oduori et al. then moved to another animal model (14), the KK-Ay mouse, which spontaneously develops a T2D phenotype. The researchers showed that while $\beta$ cells from nondiabetic control KK mice responded normally to high glucose, displaying normal electrical activity as well as GIIS, $\beta$ cells from KK-Ay mice were depolarized under all conditions, displaying a loss of GIIS. While applying GLP-1 amplified GIIS, treating with GIP had no effect. The authors concentrated on the immediate clinical implications, showing that, as they predicted, the Gq-specific agonist MK-2305 selectively enhanced glucose tolerance in these diabetic KK-Ay mice as well as in $\mathrm{K}_{\mathrm{ATP}}$ - $\mathrm{KO}$ mice. In the Discussion, the authors focused on how the change in $G$ protein signaling in chronically depolarized $\beta$ cells, in which only GLP-1 amplified insulin secretion exclusively through
Gq signaling, may have therapeutic value (Figure 1B) (14).

For the results of Oduori et al. to provide the explanation for incretin bias in T2D, T2D must involve chronic depolarization. If this chronic depolarization implication is correct, it is of the utmost fundamental importance, but is it a reasonable idea? Simplistically, perhaps yes. As we and others have previously shown (16-18) and Oduori et al. now confirm (14), simply chronically incubating normal islets in high glucose directly induces depolarization and loss of GIIS as a result of $\mathrm{K}_{\text {ATP }}$ loss. In both $\mathrm{K}_{\text {ATP }}$-KO mice (10-12) and in WT animals chronically treated with high-dose sulfonylureas (19), complete or near complete loss of $\mathrm{K}_{\mathrm{ATP}}$ activity also results in a dramatic loss of Cainduced secretion (20). Thus, a paradoxical response to hyperexcitability emerges as an inverse U-shaped relationship where $\beta$ cells initially hypersecrete insulin as $\mathrm{K}_{\mathrm{ATP}}$ density declines, but then undersecrete as $K_{\text {ATP }}$ drops to zero (20). This paradoxical hyperexcitability-induced inhibition of insulin secretion is strong enough to ensure that $\mathrm{K}_{\text {AтP }}-\mathrm{KO}$ animals are glucose intolerant and that they become overtly diabetic when insulin resistance is imposed (13). In the development of 
$\mathrm{T} 2 \mathrm{D}$, increasing insulin resistance and rising hyperglycemia result in increased $\beta$ cell excitation. If this insulin resistance and hyperglycemia are coupled to $\mathrm{K}_{\mathrm{ATP}}$ channel loss and, in turn, to chronic excitation, we predict that loss of $\mathrm{Ca}$-induced secretion must underlie the crossover to an uncompensated low-insulin, highglucose state (Figure 1A). We have shown that treating WT animals with high-dose glibenclamide also induces a crossover effect that persists in acutely isolated islets, but that is then lost within hours as the glibenclamide washes out of the tissue (19). The mechanism of crossover remains unexplained, but this rapid reversibility implies a potential mechanism for reversal of T2D. Perhaps crossover reversal underlies the counterintuitive and dramatic effects that can occur in T2D following diazoxide treatment, in which $\beta$ cell electrical activity and insulin secretion are pharmacologically suppressed (21), or when demand for insulin secretion is reduced as a result of improved insulin sensitivity following gastric bypass (22).

\section{A surprising implication}

Combining the findings relating hyperexcitability-driven failure of insulin secretion with those of Oduori et al. (14), who now show that at least one T2D model completely lacks $\mathrm{K}_{\text {ATP }}$ activity, leads us to go out on a limb and explicitly hypothesize that hyperglycemia-induced $\mathrm{K}_{\text {ATP }}$ loss and consequent chronic depolarizationinduced loss of insulin secretion might be a unifying process in the classical crossover progression of $\mathrm{T} 2 \mathrm{D}$. In other words, hyperglycemia-induced loss of $\mathrm{K}_{\mathrm{ATP}}$ might explain how T2D advances from compensated hypersecretion to undersecretion and inexorably rising glucose levels (Figure 1). We recognize that it is simplistic to think that progression from partially inhibited $\mathrm{K}_{\text {ATP }}$ channels (resulting in hypersecretion) to complete inhibition or loss of $\mathrm{K}_{\mathrm{ATP}}$ (resulting in secretion failure) is the common mechanism underlying T2D progression, but that is the implication staring us in the face!

\section{Acknowledgments}

CGN is supported by NIH grant DK109407, and MSR is supported by NIH grant DK123163.

Address correspondence to: Colin G. Nichols, Box 8228, Washington University School of Medicine, 660 S. Euclid Ave., St. Louis, Missouri 63110, USA. Phone: 314. 362.6630; Email: cnichols@wustl.edu.

1. Ahrén B. Islet $\mathrm{G}$ protein-coupled receptors as potential targets for treatment of type 2 diabetes. Nat Rev Drug Discov. 2009;8(5):369-385.

2. Prentki M, Matschinsky FM. Ca2+, cAMP, and phospholipid-derived messengers in coupling mechanisms of insulin secretion. Physiol Rev. 1987;67(4):1185-1248.

3. Baggio LL, Drucker DJ. Biology of incretins: GLP-1 and GIP. Gastroenterology. 2007;132(6):2131-2157.

4. Nauck MA, Meier JJ. The incretin effect in healthy individuals and those with type 2 diabetes: physiology, pathophysiology, and response to therapeutic interventions. Lancet Diabetes Endocrinol. 2016;4(6):525-536.

5. Ashcroft FM, Rorsman P. Electrophysiology of the pancreatic beta-cell. Prog Biophys Mol Biol. 1989;54(2):87-143.

6. Henwood MJ, et al. Genotype-phenotype correlations in children with congenital hyperinsulinism due to recessive mutations of the adenosine triphosphate-sensitive potassium channel genes. JClin Endocrinol Metab. 2005;90(2):789-794.

7. Huopio H, Shyng SL, Otonkoski T, Nichols CG. K(ATP) channels and insulin secretion disorders. Am J Physiol Endocrinol Metab. 2002;283(2):E207-E216.

8. Koster JC, et al. Hyperinsulinism induced by targeted suppression of beta cell KATP channels. Proc Natl Acad Sci U S A. 2002;99(26):16992-16997.
9. Remedi MS, et al. Hyperinsulinism in mice with heterozygous loss of K(ATP) channels. Diabetologia. 2006;49(10):2368-2378.

10. Miki T, et al. Defective insulin secretion and enhanced insulin action in KATP channeldeficient mice. Proc Natl Acad Sci U S A. 1998;95(18):10402-10406.

11. Shiota C, et al. Sulfonylurea receptor type 1 knock-out mice have intact feeding-stimulated insulin secretion despite marked impairment in their response to glucose. J Biol Chem. 2002;277(40):37176-37183.

12. Seghers V, Nakazaki M, DeMayo F, AguilarBryan L, Bryan J. Sur1 knockout mice. A model for $\mathrm{K}(\mathrm{ATP})$ channel-independent regulation of insulin secretion. J Biol Chem . 2000;275(13):9270-9277.

13. Remedi MS, et al. Diet-induced glucose intolerance in mice with decreased beta-cell ATP-sensitive K+ channels. Diabetes. 2004;53(12):3159-3167.

14. Oduori OS, et al. Gs/Gq signaling switch in $\beta$ cells defines incretin effectiveness in diabetes. J Clin Invest. 2020;130(12):6639-6655.

15. Miki T, et al. Distinct effects of glucose-dependent insulinotropic polypeptide and glucagon-like peptide-1 on insulin secretion and gut motility. Diabetes. 2005;54(4):1056-1063.

16. Shyr ZA, Wang Z, York NW, Nichols CG, Remedi MS. The role of membrane excitability in pancreatic $\beta$ cell glucotoxicity. Sci Rep. 2019;9(1):6952.

17. Glynn E, et al. Chronic glucose exposure systematically shifts the oscillatory threshold of mouse islets: experimental evidence for an early intrinsic mechanism of compensation for hyperglycemia. Endocrinology. 2016;157(2):611-623.

18. Han YE, et al. Endocytosis of $\mathrm{K}_{\mathrm{ATP}}$ channels drives glucose-stimulated excitation of pancreatic $\beta$ cells. Cell Rep. 2018;22(2):471-481.

19. Remedi MS, Nichols CG. Chronic antidiabetic sulfonylureas in vivo: reversible effects on mouse pancreatic beta-cells. PLoS Med. 2008;5(10):e206.

20. Nichols CG, Koster JC, Remedi MS. Beta-cell hyperexcitability: from hyperinsulinism to diabetes. Diabetes Obes Metab. 2007;9(suppl 2):81-88.

21. Grill V, Radtke M, Qvigstad E, Kollind M, Bjorklund A. Beneficial effects of K-ATP channel openers in diabetes: an update on mechanisms and clinical experiences. Diabetes Obes Metab. 2009;11(suppl 4):143-148.

22. Dirksen C, et al. Mechanisms of improved glycaemic control after Roux-en-Y gastric bypass. Diabetologia. 2012;55(7):1890-1901. 